\title{
Synthesis and characterization of poly(vinyl alcohol) proton exchange membranes modified with 4,4-diaminodiphenylether-2,2-disulfonic acid
}

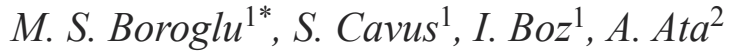 \\ ${ }^{1}$ Istanbul University, Faculty of Engineering, Chemical Engineering Department, Avcilar, 34320, Istanbul, Turkey \\ ${ }^{2}$ Gebze Institute of Technology, Materials Science and Engineering, Gebze, Kocaeli, Turkey
}

Received 24 September 2010; accepted in revised form 10 December 2010

\begin{abstract}
A proton-exchange membrane for a direct methanol fuel cell was prepared by modifying the chemical structure of poly(vinyl alcohol) (PVA) by means of sulfonation. We report the synthesis of a new proton-conducting polymer membrane with poly (vinyl alcohol) and diamine-containing organic molecules immobilized to PVA. The sulfonation was carried out by using 4,4-diaminodiphenyl ether-2,2-disulfonic acid (ODADS). A sulfonated diamine monomer, ODADS, was successfully synthesized by direct sulfonation of a commercially available diamine, 4,4-diaminodiphenyl ether (ODA), using fuming sulfuric acid as the sulfonating reagent. The chemical structure and thermal stability of the sulfonated PVA were studied by using FTIR and thermogravimetric analysis techniques, respectively. The proton conductivities of membranes were investigated as a function of ODADS content. The thermal decomposition of PVA-ODADS membranes started at $220^{\circ} \mathrm{C}$. Differential scanning calorimetry (DSC) results indicated the homogeneity of the blends. Proton conductivity values of the sulfonated PVA membranes ranged between 8.25 and $16.53 \mathrm{mS} / \mathrm{cm}$ and the conductivities of PVA-ODADS membranes increased with the increasing ODADS content.
\end{abstract}

Keywords: polymer membranes, poly(vinyl alcohol), sulfonation, polymer electrolyte membrane, proton conductivity

\section{Introduction}

Proton-conducting polymer electrolytes have been given much attention due to their possible applications in electrochemical devices such as fuel cells, humidity and gas sensors, capacitors, and electrochemical displays that work from subambient to moderately high temperatures. Direct methanol fuel cells (DMFCs), in particular, employing polymer electrolyte membranes are one of the most attractive power sources for a variety of applications [1]. The most commonly-used polymer for electrolyte membranes is the perfluorinated ionomer based polymers known by its trade name, Nafion. Nafion developed by DuPont evoked the greatest interest because of its combined chemical, electrochemical, and mechanical stabilities with high proton conductivity $\left(\sim 0.1 \mathrm{~S} \cdot \mathrm{cm}^{-1}\right)$ at ambient temperature [2]. However, this still limits the wide applications due to its high cost, high methanol permeability $\left(\sim 10^{-6} \mathrm{~cm}^{2} / \mathrm{s}\right)$ and difficulty in synthesis and processing $[3,4]$. The high methanol permeability allows the undesired transport of methanol from the anode side of the fuel cell, through the membrane, to the cathode side, a phenomenon known as methanol crossover. As a consequence, excessive methanol permeability of any polymer electrolyte membrane (PEM) leads to an unacceptable decrease in cell performance $[4,5]$. To address the problem of methanol crossover, numerous membranes as alternatives to Nafion have been developed and

\footnotetext{
${ }^{*}$ Corresponding author, e-mail: mehtap@istanbul.edu.tr
} (c) BME-PT 
studied. These studies include Nafion-based composite membranes [6], sulfonated poly (ether ether) ketone [7], sulfonated polyimide [8], polybenzimidazole [9], and sulfonated polyposphazene [10] and sulfonated poly(vinyl alcohol) (PVA) [4, 11]. Additionally, organic/inorganic hybrid membranes have been investigated, motivated by the potential for inorganic particles which can provide a physical barrier against methanol crossover while simultaneously improving mechanical and thermal stability $[12,13]$. Among the materials investigated, poly (vinyl alcohol) (PVA) is on the forefront due to its good mechanical properties, chemical stability, low cost, film forming ability, high hydrophilic behavior $[14,15]$. Cussler and co-workers [16] reported that the PVA membranes employed in pervaporation process were much better methanol barriers than Nafion membrane. However, PVA membranes are poor proton conductors as compared with Nafion membrane because the PVA itself does not have any negative charged ions, such as, carboxylic and sulfonic acid groups. Therefore, PVA has to be modified to induce proton conductivity. Shao et al. [17] developed a membrane for DMFC by coating Nafion with PVA. Methanol resistance of the membrane increased at the expense of its proton conductivity. In addition, interfacial adhesion between the two polymeric phases has yet to be improved. Here, we have taken the view that the PVA membranes could be used as a PEM in fuel cell applications if the negative ions are held within their structure.

In this work, we report a new proton-conducting polymer membrane with poly (vinyl alcohol) and diamine-containing organic molecules immobilized to PVA to analyze the proton conductivity, methanol permeability, and physical properties. The introduction of sulfonic acid group to polymer structure was achieved by using a sulfonated diamine monomer, 4,4'-diaminodiphenyl ether-2,2'-disulfonic acid (ODADS). Sulfonation degree could be precisely controlled by regulating the weight ratio between PVA and ODADS during polymerization process. It is well-known that the control of sulfonation degree is very important because high sulfonation degree generally leads to high swelling degree or even dissolution of the membranes in water. On the other hand, low sulfonation degree generally results in poor proton conductivity, and therefore it seems that improving membrane stability and enhancing proton conductivity are contradictory to each other. In this paper, a sulfonated diamine monomer, 4,4'diaminodiphenyl ether- 2,2'-disulfonic acid (ODADS), was synthesized, and a series of polymer blends were prepared. The introduction of negative charged ion group in the PVA membrane was achieved by the immobilization of ODADS. We compared diamine-immobilized PVA with the ones reported in open literature. The resultant membranes are thus capable of possessing all the required properties of a proton exchange membrane, namely, reasonable swelling, good mechanical strength, and low methanol permeability along with the high proton conductivity due to trapped ODADS chains in the PVA network. Physical properties, proton conductivity, and water stability of these membranes were also investigated.

\section{Experimental \\ 2.1. Materials}

Poly(vinyl alcohol) (PVA, 99.5\% hydrolyzed, $M_{\mathrm{w}}=$ $72000 \mathrm{~g} / \mathrm{mol}$ ) was supplied from Merck Co. Ltd., Hohenbrunn, Germany. 4,4'-diaminodiphenyl ether (ODA) of $98.2 \%$ purity was purchased from the Sigma-Aldrich Chemical Co. Ltd., St. Louis, USA and used as received. ODA was converted into 4,4'diaminodiphenyl ether-2,2'-disulfonic acid (ODADS) using concentrated sulfuric acid (\%95, SigmaAldrich Chemical Co. Ltd., Seelze, Germany) and fuming sulfuric acid $\left(\mathrm{SO}_{3}, 60 \%\right.$, Sigma-Aldrich Chemical Co. Ltd., Seelze, Germany). For the synthesis of sulfonated polymers, dimethylsulfoxide (DMSO, Merck Co. Ltd., Hohenbrunn, Germany) was used as solvent and used as received. Methanol was an analytical-grade solvent obtained from Sigma-Aldrich Chemical Co. Ltd., Seelze, Germany and the distilled water was also used in this study.

\subsection{Synthesis of $4,4^{\prime}$-diaminodiphenyl ether-2,2'-disulfonic acid (ODADS)}

A $100 \mathrm{ml}$ three-neck flask equipped with a mechanical stirring device was charged $2.00 \mathrm{~g}(10.0 \mathrm{mmol})$ of 4,4'-diaminodiphenyl ether (ODA). The flask was cooled in an ice bath, and then $2.5 \mathrm{ml}$ of concentrated (95-97\%) sulfuric acid was slowly added while stirring. After ODA was completely dissolved, $3.5 \mathrm{ml}$ of fuming $\left(\mathrm{SO}_{3} 60 \%\right)$ sulfuric acid was slowly added to the flask. The reaction mixture was stirred at $0^{\circ} \mathrm{C}$ for $2 \mathrm{~h}$ and then slowly heated to 


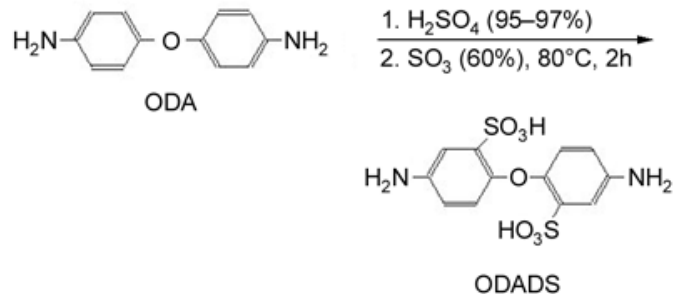

Figure 1. Synthetic pathway of 4,4'-diaminodiphenyl ether2,2'-disulfonic acid (ODADS)

$80^{\circ} \mathrm{C}$ and kept at this temperature for $2 \mathrm{~h}$. After cooling to room temperature, the slurry was carefully poured into $30 \mathrm{~g}$ of crushed ice. The resulting white precipitate was filtered off and then redissolved in a sodium hydroxide solution. The basic solution was filtered, and the filtrate was acidified with concentrated hydrochloric acid. The solid was filtered off, washed with water and methanol successively, and dried at $80^{\circ} \mathrm{C}$ in vacuo. Then $3.05 \mathrm{~g}$ of white product was obtained giving a yield of $85 \%$. Figure 1 and 2 show the reaction pathways of ODADS and FTIR spectra of ODADS.

FTIR spectroscopy was used to confirm the presence of the pendant $-\mathrm{SO}_{3} \mathrm{H}$ group on the monomer structure. Sulfonation of ODADS is confirmed by the presence of two sharp peaks at 1104 and $1023 \mathrm{~cm}^{-1}$, which are due to the aromatic $\mathrm{SO}_{3} \mathrm{H}$ symmetric and asymmetric stretching vibrations,

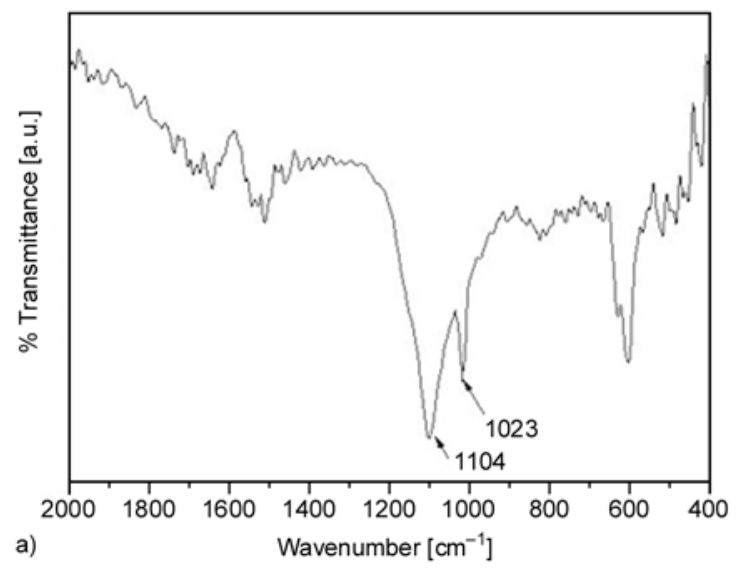

respectively. The absorption bands at $3540 \mathrm{~cm}^{-1}$ are attributed to the stretching vibration of the hydroxyl $-\mathrm{OH}$ group shown in Figures $2 \mathrm{~b}$. The presence of the benzene rings in ODA is established by the $=\mathrm{C}-\mathrm{H}$ stretching vibration at $3050 \mathrm{~cm}^{-1}$ and in the region of $1650-1400 \mathrm{~cm}^{-1}$. There are bands recognized as vibrations in the plane of aromatic ring $v \mathrm{C}_{\mathrm{Ar}} \mathrm{C}_{\mathrm{Ar}}$ $\left(1467 \mathrm{~cm}^{-1}\right)$ and antisymmetric and symmetric deformation bands of $\mathrm{NH}_{2}$ group $\left(1517 \mathrm{~cm}^{-1}\right)$. The $\mathrm{C}-\mathrm{N}$ streching vibrations are located at $1365 \mathrm{~cm}^{-1}$. The doublet of $v \mathrm{CCN}$ bands is observed at $914,830 \mathrm{~cm}^{-1}$, respectively $[8,18,19]$.

\subsection{Membrane preparation}

$10 \mathrm{wt} \%$ PVA solution was prepared by dissolving the preweighed amount of PVA in DMSO at $90^{\circ} \mathrm{C}$ for at least $6 \mathrm{~h}$. PVA solutions were mixed with the various amounts of ODADS by the weight ratios of the PVA $(5-30 \%)$ and then the mixtures were vigorously stirred at $80^{\circ} \mathrm{C}$ for $24 \mathrm{~h}$. Then, PVA solution was cast onto a teflon sheet. The solvent was removed by evaporation at room temperature for $24 \mathrm{~h}$ and then the cast membranes were allowed to dry at $60^{\circ} \mathrm{C}$ for $24 \mathrm{~h}$. Finally, the dry membranes were subjected to thermal treatment at $120^{\circ} \mathrm{C}$. Membrane thickness was measured with probe using magnetic induction principle. Measurements were

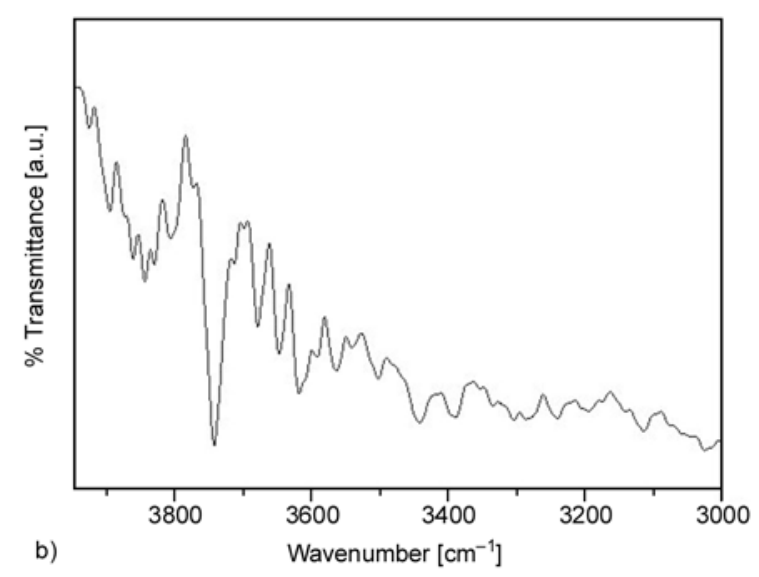

Figure 2. FTIR spectra of ODADS monomer a) at 2000-400 $\mathrm{cm}^{-1}$ region, b) at 4000-3000 $\mathrm{cm}^{-1}$ region

Table 1. Experimental conditions and maximum proton conductivities of polymers

\begin{tabular}{|l|c|c|c|c|c|c|c|}
\hline \multicolumn{1}{|c|}{ Samples } & $\begin{array}{c}\text { ODADS/PVA } \\
\text { [weight ratio] }\end{array}$ & $\begin{array}{c}\mathbf{\%} \mathbf{5} \\
\mathbf{W . L}\end{array}$ & $\begin{array}{c}\text { Residue \% } \\
{\left[\mathbf{7 5 0}^{\circ} \mathbf{C}\right]}\end{array}$ & $\begin{array}{c}\mathbf{T}_{\mathbf{g}} \\
{\left[{ }^{\circ} \mathbf{C}\right]}\end{array}$ & $\begin{array}{c}\text { Maximum proton } \\
\text { conductivity } \\
{[\mathbf{m S / c m}]}\end{array}$ & $\begin{array}{c}\text { Methanol } \\
\text { permeability } \\
[\mathbf{m o l} / \mathbf{( c m} \cdot \mathbf{s})]\end{array}$ & $\begin{array}{c}\text { Water uptake } \\
{[\%]}\end{array}$ \\
\hline PVA-ODADS (T1) & 5 & 73 & 3.04 & 71 & 4.24 & $1.27 \cdot 10^{-11}$ & 86.39 \\
\hline PVA-ODADS (T2) & 10 & 69 & 8.15 & 89 & 8.25 & $7.70 \cdot 10^{-10}$ & 98.65 \\
\hline PVA-ODADS (T3) & 15 & 93 & 8.45 & 96 & 15.35 & $3.45 \cdot 10^{-11}$ & 83.77 \\
\hline PVA-ODADS (T4) & 20 & 116 & 15.15 & 95 & 16.53 & $7.65 \cdot 10^{-11}$ & 69.94 \\
\hline PVA-ODADS (T5) & 30 & 123 & 17.12 & 93 & 6.90 & $8.70 \cdot 10^{-11}$ & 45.18 \\
\hline Nafion 117 & - & - & - & - & 19.78 & $1.76 \cdot 10^{-9}$ & - \\
\hline
\end{tabular}




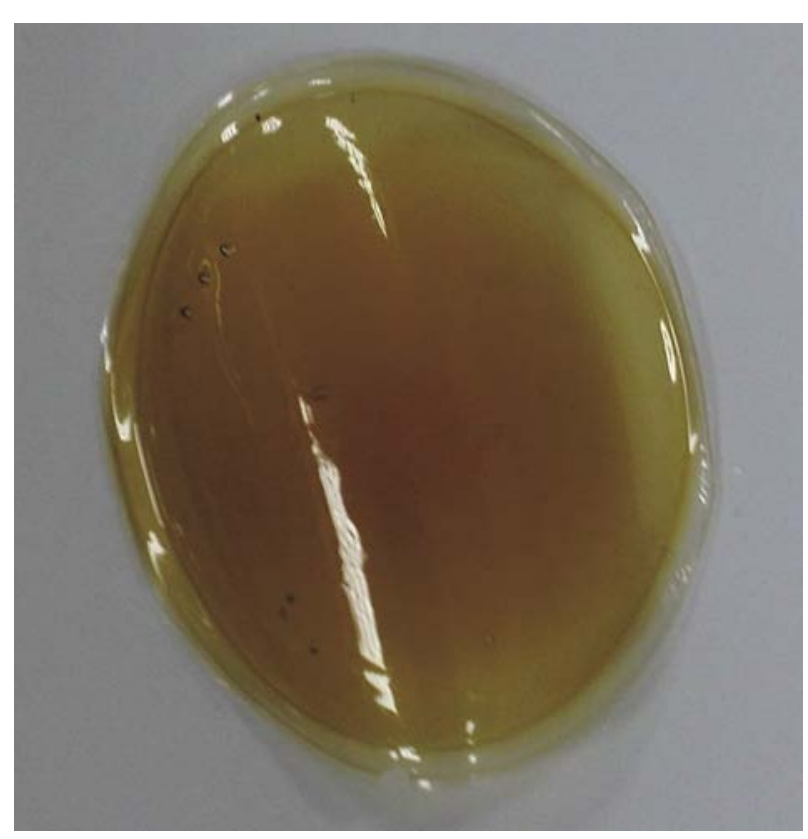

Figure 3. Homogeneous, transparent PVA-ODADS membrane

carried out with a Mega-Check FN coating thickness gauge $(0-2000 \mu \mathrm{m})$, List Magnetic, Echterdingen, Germany. For each sample, at least 20 measurements were taken from various regions and average membrane thickness of $120 \pm 8 \mu \mathrm{m}$ was obtained. The membranes were stored in deionized water after pretreatment in order to ensure equilibration prior to use in conductivity measurements. The experimental conditions used to prepare the polymer solutions and the nomenclatures used for each sample are shown in Table 1. Transparent, hygroscopic and free standing films (Figure 3) were obtained in all the samples.

\subsection{Membrane characterization}

To demonstrate the presence of immobilized diaminecontaining organic molecules on the PVA membrane, membranes were examined by the Fourier transform infrared (FT-IR) spectra. IR spectra were recorded on a Bruker Alpha-P ATR spectrophotometer with a resolution of $4 \mathrm{~cm}^{-1}$ in the range of $400-4000 \mathrm{~cm}^{-1}$.

Thermal degradation experiments were carried out in Shimadzu TGA-50 Thermogravimetric Analyzer. Thermal analyses were completed on thin films having an average mass of $15 \mathrm{mg}$. The samples $(\sim 10 \mathrm{mg})$ were heated from room temperature to $850^{\circ} \mathrm{C}$ under $\mathrm{N}_{2}$ atmosphere at a heating rate of $10^{\circ} \mathrm{C} / \mathrm{min}$.
Glass transition temperatures were determined with Mettler-Toledo DSC 822. Test samples were heated from 25 to $250^{\circ} \mathrm{C}$ at a rate of $10^{\circ} \mathrm{C} \mathrm{min}^{-1}$ under nitrogen atmosphere in the first DSC cycle and then cooled from 250 to $25^{\circ} \mathrm{C}$ at the rate of $10^{\circ} \mathrm{C} \cdot \mathrm{min}^{-1}$, and finally subjected to the same procedure in the second cycle. The measurements were made under nitrogen gas with a flow rate of $20 \mathrm{~cm}^{3} \cdot \mathrm{min}^{-1}$, up to $250^{\circ} \mathrm{C} . T_{\mathrm{g}}$ of the sample was determined as the midpoint temperature of the transition region in the second heating cycle.

Methanol permeability was measured using our homemade test cell with a volume of $4 \mathrm{ml}$ [20]. The cell was filled with $2 \mathrm{ml}$ of methanol. Methanol vapor was in equilibrium with the liquid at the bottom of the cell. Methanol vapor diffused through the membrane, which was clamped between the mouth of glass and the cap with a hole on. The cap had a $0.84 \mathrm{~cm}$ diameter opening hole through which the methanol diffused into surronding air. The weight loss caused by the diffusion of methanol through membrane was recorded as a function of time and the data were used for permeability calculations. Molar methanol flux $(J)$ through a PVA-ODADS membranes was calculated using Equation(1). Nafion 112, with known permeability, was used as a reference. The methanol permeability of composite membranes $(P)$ was calculated using molar flux $(J)$ shown in Equation $(2)[14]$ :

$$
\begin{aligned}
& J=\frac{W \cdot l}{M_{\mathrm{w}} \cdot A \cdot t} \\
& \frac{J_{1}}{J_{2}} \cdot \frac{l_{1}}{l_{2}}=\frac{P_{1}}{P_{2}}
\end{aligned}
$$

where $J=$ flux, $W=$ weight loss [g], $l=$ thickness $[\mathrm{cm}], A=$ area $\left[\mathrm{cm}^{2}\right], t=$ time $[\mathrm{s}]$.

Thickness of the films does not change after adding with ODADS groups leading the cancellation of the thickness values $(l)$ in Equation (2). Therefore, permeability is directly proportional to the molar flux. Samples dried in vacuum oven at $40^{\circ} \mathrm{C}$ for $48 \mathrm{~h}$ cut into $2 \mathrm{~cm}^{2}$ squares and then each sample being weighed in the dry state before swelling in water at room temperature $\left(20^{\circ} \mathrm{C}\right)$. Afterwards, samples were immersed in deionized water for at least $24 \mathrm{~h}$, dabbed for removal of surface water, and then immediately weighed. Water uptake was calculated by the Equation (3): 
$W[\%]=\frac{W_{\text {wet }}-W_{\text {dry }}}{W_{\text {dry }}} \cdot 100$

Proton conductivities of the modified PVA membranes were measured by using a four-point probe technique. The conductivity of the membranes was measured by BT-1005 BekkTech Scanning DC Software. The membrane was cut into a $1 \mathrm{~cm} \times 2 \mathrm{~cm}$ strip and immersed in the deionized water for $12 \mathrm{~h}$ prior to the measurement. For uniform water content in the membrane, the cell along with the sample was immersed in deionized water.

\section{Results and discussion}

\subsection{FT-IR study}

Figures 4 shows FTIR spectra of PVA and PVA modified with ODADS, respectively. From Figure 4, a broad peak at a wavenumber ranging between 3000 and $3400 \mathrm{~cm}^{-1}$, representing the hydroxyl group of PVA, can be observed. In addition, a small sharp peak at $1720 \mathrm{~cm}^{-1}$ was noted. This small sharp peak is attributed to the presence of some residual vinyl acetate repeating units in the $99.5 \%$ hydrolyzed PVA molecules. After performing the sulfonation, the peaks at $1011-1045 \mathrm{~cm}^{-1}$ attributed to symmetric vibration of the sulfonic group [21]. Peaks at $1218-1270 \mathrm{~cm}^{-1}$ associate with the symmetric stretching vibration of the $-\mathrm{SO}_{3}^{-}$group. Also $\mathrm{C}-\mathrm{N}$ streching vibrations are located at 1320 and $837 \mathrm{~cm}^{-1}$. Membranes have a peak at $1640 \mathrm{~cm}^{-1}$ due to amine $\mathrm{NH}_{2}$ bending vibration. Intensity of the $\mathrm{N}-\mathrm{H}$ bond

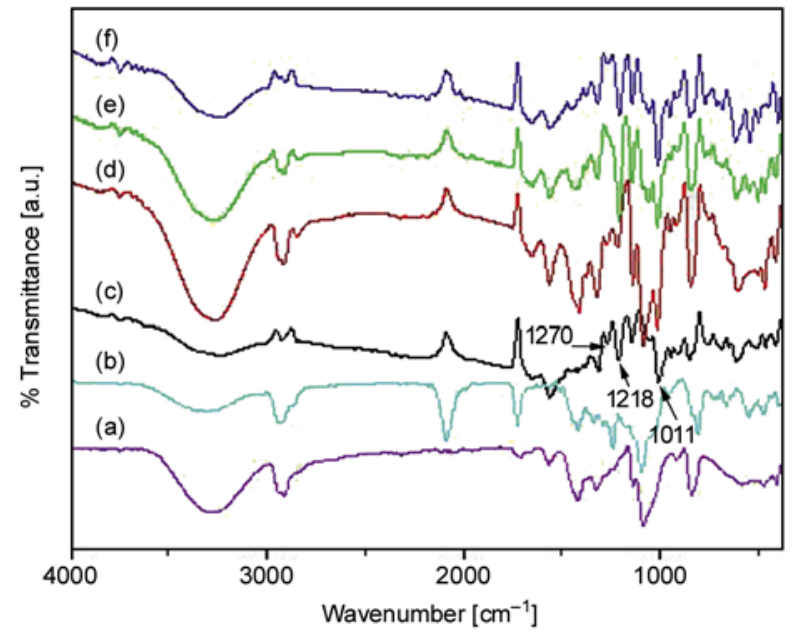

Figure 4. FT-IR spectra of a) PVA monomer, b) PVAODADS-5\% (T1), c) PVA-ODADS-10\% (T2), d) PVA-ODADS- $15 \%$ (T3), e) PVA-ODADS$20 \%$ (T4), and f) PVA-ODADS-30\% (T5) series polymers increased with the ODADS content of the membrane. Additionally, the absorption band at $1640 \mathrm{~cm}^{-1}$ indicates the protonated ODADS from the freenitrogen (unprotonated) side. These results suggest that the $-\mathrm{SO}_{3} \mathrm{H}$ group deprotonates by doping with ODADS and forms $-\mathrm{SO}_{3}^{-}$group. Our results also demonstrated that the proton conduction occurs by jumping of protons from a protonated ODADS to a non-protonated one, to sulfonic acid functional groups of PVA-ODADS [22]. These spectroscopically specific observations prove that ODADS participated in the PVA network.

\subsection{Thermal analysis}

Differantial Scanning Calorimetry measurements were carried out by a heating-cooling-heating cycle, so-called the $\mathrm{H}-\mathrm{C}-\mathrm{H}$ procedure. The purpose of the first heating cycle was to remove any thermal history of the PVA composite membrane. The glass transition temperatures $\left(T_{\mathrm{g}}\right)$ of the PVA/ODADS membranes with various ODADS compositions (5$30 \mathrm{wt} \%$ ) are listed in Table 1 . The glass transition temperature of the pure PVA was reported to be near $85^{\circ} \mathrm{C}$ [23]. The immobilized membranes exhibited glass transition temperature $\left(T_{\mathrm{g}}\right)$ at slightly higher values than the pure PVA. For the samples with different ODADS contents, the glass transition temperature $\left(T_{\mathrm{g}}\right)$ appearing around $90^{\circ} \mathrm{C}$, slightly shifted to higher temperature for higher ODADS content. The raise in $T_{\mathrm{g}}$ was possibly caused by the hydrogen bonding of the ODADS units which suppressed the segmental mobility of the polymers. Also as it is seen on Table 1, the existence of single $T_{\mathrm{g}}$ for all the samples indicates the homogenity of the membranes.

In Figure 5, the thermal degradation profiles of PVA-ODADS membranes illustrated changing the ODADS contents and $5 \mathrm{wt} \%$ weight loss and the residual ashes at $750^{\circ} \mathrm{C}$ were also listed in Table 1. Here, it is found that the weight-loss profiles are very similar to each other but the onset temperatures of thermal degradation and the residual weight [\%] at $750^{\circ} \mathrm{C}$ are different in all materials. PVAODADS membranes exhibited three weight loss stages at $50-140,230-320$ and $370-460^{\circ} \mathrm{C}$ followed by the final decomposition of the polymer that began around $460^{\circ} \mathrm{C}$. As seen in Figure 5, for the PVA-ODADS membranes the first weight loss region (occurring between temperatures of $T=50$ 


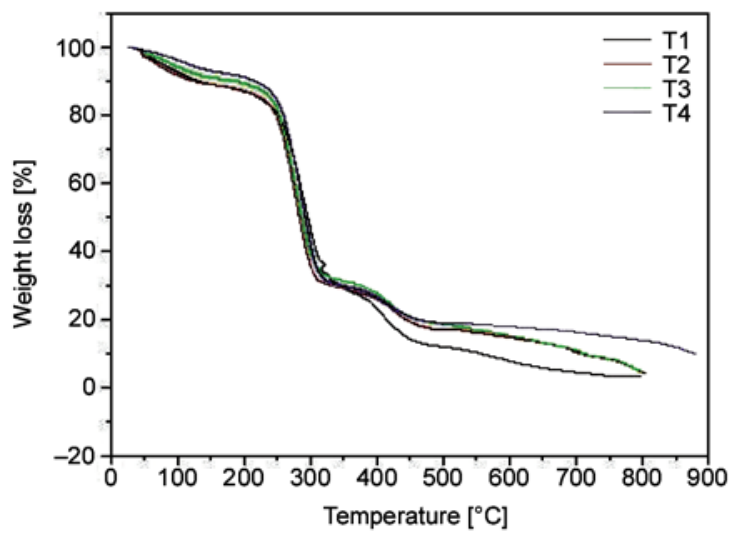

Figure 5. TG thermograms of PVA-ODADS membranes at a heating rate of $10^{\circ} \mathrm{C} / \mathrm{min}$ in inert atmosphere

$140^{\circ} \mathrm{C}$ ) corresponds to the loss of water in membranes. The second weight loss region (occurring between temperatures of $T=230-320^{\circ} \mathrm{C}$ ) corresponds to the loss of sulfonic acid due to the desulfonation of sulfosuccinic acid. In the third weight loss region (at temperatures $>370^{\circ} \mathrm{C}$ ) the polymer residues were further degraded at $T=370^{\circ} \mathrm{C}$, which corresponds to the decomposition of the main chains of the PVA. The temperature corresponding to a $5 \mathrm{wt} \%$ weight loss in the course of thermoxidative degradation increased with increasing content of ODADS. It was possible to state that ODADS addition increased thermal stability of the structure about $50^{\circ} \mathrm{C}$ upwards. Additionally, as shown in Figure 5, an increase of the ODADS content leads to an increase of the residual char remaining at the final temperature $\left(750^{\circ} \mathrm{C}\right)$. This indicates that the immobilization of PVA by ODADS is partially attributed to the improvement of the thermal stability of the PVA-ODADS membranes and, also in this study, we found that these types of membranes are stable up to $220^{\circ} \mathrm{C}$ without loosing their mechanical strength and functional properties. TGA results did not provide enough information about the microstructure of final membranes. However, we can expect that the relative difference of weight loss observed in Figure 5 may be due to uniform immobilization of ODADS.

\subsection{Methanol permeability}

Methanol crossover is still an unresolved problem in direct methanol fuel cells, especially for portable applications where the current densities are already relatively low. Fuel crossover at high methanol concentrations from anode side to the cathode side

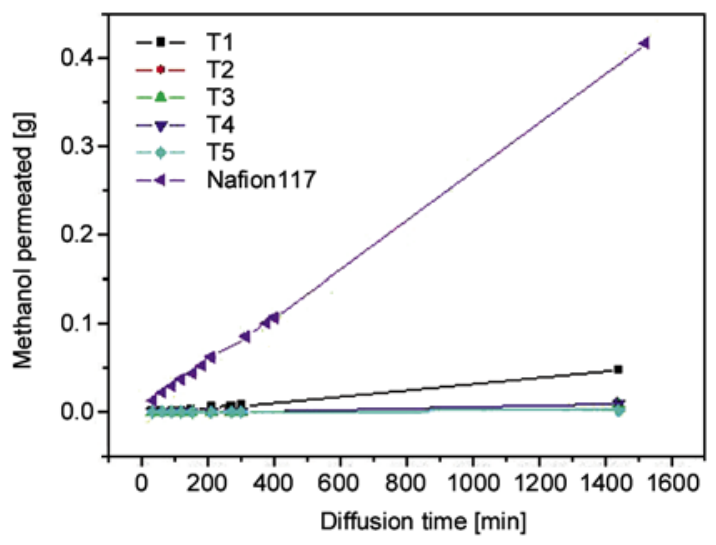

Figure 6. Mass flow of methanol through PVA-ODADS membranes

causes polarization losses. In this study, methanol permeability of the composite membranes was measured by simple homemade test cell similar to the study of Gasa et al. [24]. The cell is filled with $2 \mathrm{ml}$ methanol and the mass flow is recorded as a function of time (Figure 6). Figure 6 shows the mass flow of methanol permeated through membranes in the cell, as a function of time. Here, the methanol permeation increased linearly with time. In addition to their attractive proton conductivity values, PVA-ODADS membranes also featured attractive methanol barrier properties. Table 1 showed methanol permeability values of blend membranes. For a comparison, methanol permeability of Nafion 117 was measured under the same experimental conditions, yielding a value of $1.76 \cdot 10^{-9} \mathrm{~mol} /(\mathrm{cm} \mathrm{s})$. The methanol permeation value of blend membranes was appreciably small compared to that of Nafion 117. For PVA-ODADS membranes, the methanol permeability increased with ODADS content, due to an increased number of hydrophilic sulfonic acid groups attached to ODADS. Thus, ODADS content plays a key role in methanol permeability, indicating that the ODADS moieties may interfere with methanol permeation in some manner, while facilitating proton transport through the sulfonic acid groups.

\subsection{Water uptake (WU)}

Figure 7 presents the WU of the PVA-ODADS membranes plotted as a function of ODADS content in the polymer blend, respectively. Water uptake values of the membranes modified with ODADS are relatively high. This is probably due to the immobilization of ODADS in PVA might lead to more rigid 


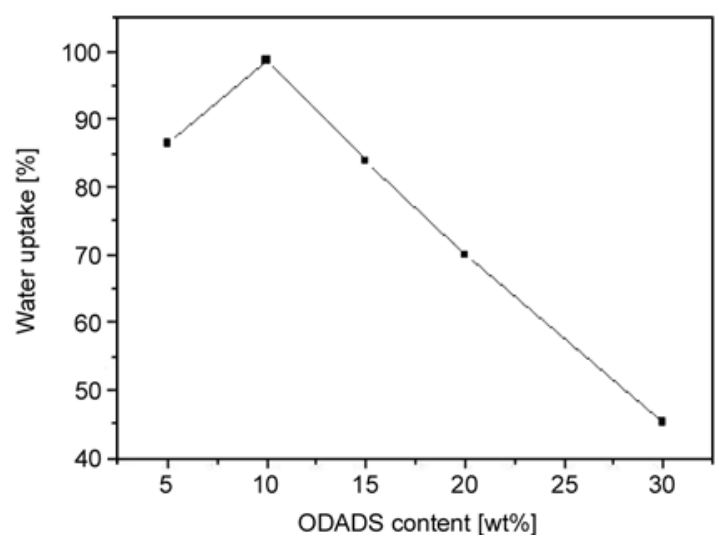

Figure 7. Water uptake versus ODADS content of the PVA/ODADS membrane

and compact polymer structure and resulted in a decrease in the free volume capable of containing water molecules. Also, some water-absorption sites of PVA-ODADS membrane were blocked with $-\mathrm{SO}_{3} \mathrm{H}$ groups. The blocking effect could also be attributed to the presence of $\mathrm{SO}_{3} \mathrm{H} / \mathrm{PVA}$ interaction, which reduces the swelling ability of PVA in water.

\subsection{Conductivity}

The proton conductivity measurements of the membrane were carried out at a $100 \% \mathrm{RH}$ as a function of ODADS content by using a four-point probe technique and the results are shown in Figure 8. The proton conductivities of the membranes measured at $T=30^{\circ} \mathrm{C}$ were in the range $10^{-3}$ to $10^{-2} \mathrm{~S} / \mathrm{cm}$. The conductivity of Nafion 117 measured with our test system is also included for comparison purposes. The membranes made of PVA-ODADS exhibited proton conductivities 4.24 and $16.53 \mathrm{mS} / \mathrm{cm}$. The proton conductivity of blend membranes increased with the increase of ODADS content. The conductivities initially increased with the amount of ODADS,

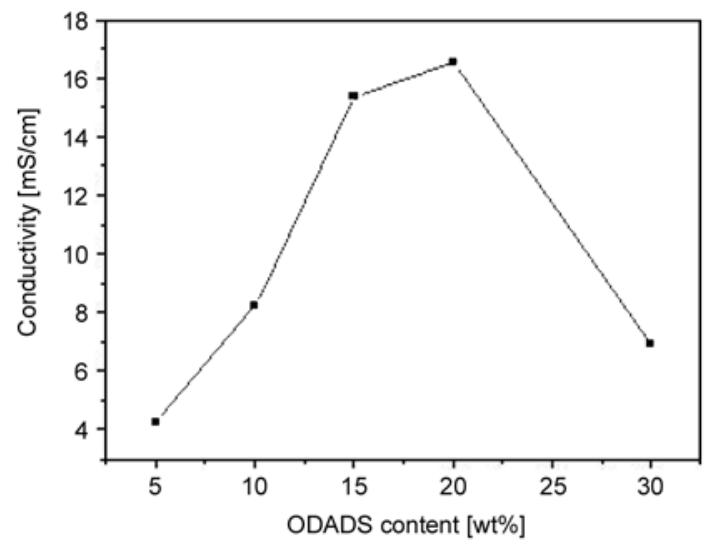

Figure 8. Proton conductivity as a function of ODADS content at $30^{\circ} \mathrm{C}$ up to the maximum value of $16.53 \mathrm{mS} / \mathrm{cm}$. After that, the proton conductivity of the PVA membranes decreased again as the amount of ODADS used was above $20 \%$. The maximum poton conductivity value herein is comparable to that of the Nafion 117 membrane measured in this study $(19.78 \mathrm{mS} / \mathrm{cm})$. The initial increase in proton conductivity of the membrane can be ascribed to the greater content of sulfonic acid groups in the modified PVA molecules, which is responsible for conducting protons. However, the proton conductivity of a membrane is not only dependent on the degree of sulfonation of the polymer, it also changes with water uptake of the membrane. For example, it was reported [25] that the proton conductivity of the Nafion membrane decreased remarkably when the membrane was operated at a temperature above the boiling point of the water. This is because water molecules serve as the 'vehicles' for the transportation of the protons from anode to cathode [26]. In this study, the water uptake values of the sulfonated PVA membranes decreased with the amount of sulfonic acid added (Table 1) and so a decrease in proton conductivity with the amount of ODADS could be expected. Therefore, there should be an optimum value of the amount of ODADS used, in which the effect of the degree of sulfonation and the effect of water uptake on proton conductivities of the sulfonated PVA membranes are compromised. In this study, the optimum value of the amount of the ODADS is found to be $20 \%$ by weight. Beyond this value, the water uptake became the predominating factor affecting the proton conductivities of the membrane in negative manner.

Even though the proton conductivity value of the blend membranes was lower than that of Nafion. PVA-ODADS membranes showed quite low values of methanol permeability, it showed the high impact in the application of DMFC.

In general, proton conductive mechanism through these membranes is well known to occur by two routes $[26,27]$. The first route is hopping mechanism, also known as the Grotthuss model, wherein a proton is passed down a chain of water molecules. The protons are transferred from one vehicle to the other by hydrogen bonds (proton hopping). The second route is a vehicle mechanism, wherein a proton combines with solvent molecules, producing a complex like $\mathrm{H}_{3} \mathrm{O}^{+}$or $\mathrm{CH}_{3} \mathrm{OH}_{2}^{+}$. This complex 
then diffuses intact. These two principal mechanisms essentially reflect the difference in nature of the hydrogen bond formed between the protonated species and their environment. In membranes which support strong hydrogen bonding, the Grotthuss mechanism is preferred; the vehicle mechanism is characteristic of species with weaker bonding [26]. The proton conductivity occurs by transport of larger complexes such as $\mathrm{H}_{3} \mathrm{O}^{+}, \mathrm{H}_{5} \mathrm{O}_{2}^{+}, \mathrm{H}_{7} \mathrm{O}_{3}^{+}$or $\mathrm{CH}_{3} \mathrm{OH}_{2}^{+}$or some similar methanol containing complex [27]. In addition, the protons of these complexes are transferred from one vehicle to another. Therefore, the proton conductive mechanism was occurring by two simultaneous routes.

Previously Seeponkai and Wootthikanokkhan [28] prepared sulfonated PVA by reacting the PVA with sulfoacetic acid and poly (acrylic acid). This PVA membrane exhibited a maximum proton conductivity of $6.35 \mathrm{mS} / \mathrm{cm}$ at $15 \%$ sulfoacetic acid content under hydrous condition. Kim et al. [29] prepared PVA/PAA/sulfosuccinic acid/silica hybrid membranes and reported that the maximum conductivity reached was approximately $8.0 \mathrm{mS} / \mathrm{cm}$ for PVA/ $\mathrm{PAA} / \mathrm{SSA}$ at $25^{\circ} \mathrm{C}$. In this study, maximum proton conductivity of $16.53 \mathrm{mS} / \mathrm{cm}$ at $30^{\circ} \mathrm{C}$ was obtained for PVA-ODADS (T4) which is relatively better than PVA based polymers synthesized in the literature.

\section{Conclusions}

In the present work, a new proton-conducting polymer membrane with poly(vinyl alcohol) and diaminecontaining sulfonic acid group immobilized to PVA was prepared and also evaluated as a potential polymer electrolyte membrane in direct methanol fuel cell applications. Especially, 4,4'-diaminodiphenyl ether-2,2'-disulfonic acid was effectively introduced as an immobilization agent and a donor of negative charged ion $\left(-\mathrm{SO}_{3} \mathrm{H}\right)$ in the preparation of the PVA-ODADS membranes. Thermal stabilities of membranes were characterized by TGA and found that PVA-ODADS membranes were thermally stable up to $220^{\circ} \mathrm{C}$. From differential scanning calorimetry $T \mathrm{~g}$ of the PVA membrane materials were found to have increased with the increasing of ODADS content. The proton conductivity of these materials increased with ODADS content. The PVA-ODADS materials exhibited maximum proton conductivity of $16.53 \mathrm{mS} / \mathrm{cm}$ at $30^{\circ} \mathrm{C}$. Compared to the other membranes, the PVA-ODADS containing $20 \%$ of ODADS showed high proton conductivity. The membranes made from PVA-ODADS also appeared to be good candidates for direct methanol fuel cells because of their low methanol permeability. The methanol permeability of values of membranes were much lower than that of the Nafion membrane.

\section{References}

[1] Ludvigsson M., Lindgren J., Tegenfeldt J.: Crystallinity in cast Nafion. Journal of the Electrochemical Society, 147, 1303-1305 (2000).

DOI: $10.1149 / 1.1393354$

[2] Qiao J., Hamaya T., Okada T.: New highly proton-conducting membrane poly(vinylpyrrolidone)(PVP) modified poly(vinyl alcohol)/2-acrylamido-2-methyl-1propanesulfonic acid (PVA-PAMPS) for low temperature direct methanol fuel cells (DMFCs). Polymer, 46, 10809-10816 (2005).

DOI: 10.1016/j.polymer.2005.09.007

[3] Chang Y-W., Wang E., Shin G., Han J-E., Mather P. T.: Poly(vinyl alcohol) (PVA)/sulfonated polyhedral oligosilsesquioxane (sPOSS) hybrid membranes for direct methanol fuel cell applications. Polymers for Advanced Technologies, 18, 535-543 (2007). DOI: $10.1002 /$ pat.913

[4] Rhim J-W., Park H. B., Lee C-S., Jun J-H., Kim D. S., Lee Y. M.: Crosslinked poly(vinyl alcohol) membranes containing sulfonic acid group: Proton and methanol transport through membranes. Journal of Membrane Science, 238, 143-151 (2004).

DOI: 10.1016/j.memsci.2004.03.030

[5] Barragán V. M., Ruiz-Bauzá C., Villaluenga J. P. G., Seoane B.: Transport of methanol and water through Nafion membranes. Journal of Power Sources, 130, 22-29 (2004).

DOI: 10.1016/j.jpowsour.2003.12.007

[6] Dimitrova P., Friedrich K. A., Stimming U., Vogt V.: Modified Nafion ${ }^{\circledR}$-based membranes for use in direct methanol fuel cells. Solid State Ionics, 150, 115-122 (2002). DOI: 10.1016/S0167-2738(02)00267-9

[7] Li L., Zhang J., Wang Y. : Sulfonated poly(ether ether ketone) membranes for direct methanol fuel cell. Journal of Membrane Science, 226, 159-167 (2003).

DOI: $10.1016 /$ j.memsci.2003.08.018

[8] Fang J., Guo X., Harada S., Watari T., Tanaka K., Kita H., Okamoto K-I.: Novel sulfonated polyimides as polyelectrolytes for fuel cell application. 1. Synthesis, proton conductivity, and water stability of polyimides from 4,4'-diaminodiphenyl ether-2,2'-disulfonic acid. Macromolecules, 35, 9022-9028 (2002).

DOI: $10.1021 / \mathrm{ma} 020005 \mathrm{~b}$ 
[9] Lobato J., Cañizares P., Rodrigo M. A., Linares J. J.: PBI-based polymer electrolyte membranes fuel cells: Temperature effects on cell performance and catalyst stability. Electrochimica Acta, 52, 3910-3920 (2007). DOI: 10.1016/j.electacta.2006.11.014

[10] Guo Q., Pinaturo P. N., Tang H., O’Connor S.: Sulfonated and crosslinked polyphosphazene-based proton-exchange membranes. Journal of Membrane Science, 154, 175-181 (1999).

DOI: 10.1016/S0376-7388(98)00282-8

[11] Kim D. S., Park H. B., Rhim J. W., Lee Y. M.: Preparation and characterization of crosslinked $\mathrm{PVA} / \mathrm{SiO}_{2}$ hybrid membranes containing sulfonic acid groups for direct methanol fuel cell applications. Journal of Membrane Science, 240, 37-48 (2004).

DOI: $10.1016 /$ j.memsci.2004.04.010

[12] Su Y-H., Liu Y-L., Sun Y-M., Lai J-Y., Guiver M. D., Gao Y.: Using silica nanoparticles for modifying sulfonated poly(phthalazinone ether ketone) membrane for direct methanol fuel cell: A significant improvement on cell performance. Journal of Power Sources, 155, 111-117 (2006).

DOI: 10.1016/j.jpowsour.2005.03.233

[13] Manea C., Mulder M.: Characterization of polymer blends of polyethersulfone/sulfonated polysulfone and polyethersulfone/sulfonated polyetheretherketone for direct methanol fuel cell applications. Journal of Membrane Science, 206, 443-453 (2002)

DOI: $10.1016 / \mathrm{S} 0376-7388(01) 00787-6$

[14] Lebrun L., Silva A. D., Metayer M.: Elaboration of ion-exchange membranes with semi-interpenetrating polymer networks containing poly(vinyl alcohol) as polymer matrix. Journal of Applied Polymer Science, 84, 1572-1580 (2002). DOI: $10.1002 / a p p .10420$

[15] Hirankumar G., Selvasekarapandian S., Bhuvaneswari M. S., Baskaran R., Vijayakumar M.: AC impedance studies on proton conducting polymer electrolyte complexes (PVA $+\mathrm{CH}_{3} \mathrm{COONH}_{4}$ ). Ionics, 10, 135-138 (2004).

DOI: $10.1007 / \mathrm{BF} 02410322$

[16] Pivovar B. S., Wang Y., Cussler E. L.: Pervaporation membranes in direct methanol fuel cells. Journal of Membrane Science, 154, 155-162 (1999).

DOI: 10.1016/S0376-7388(98)00264-6

[17] Shao Z-G., Wang X., Hsing I-M.: Composite Nafion/ polyvinyl alcohol membranes for the direct methanol fuel cell. Journal of Membrane Science, 210, 147-153 (2002).

DOI: $10.1016 / \mathrm{S} 0376-7388(02) 00386-1$

[18] Watari T., Fang J., Tanaka K., Kita H., Okamoto K-I., Hirano T.: Synthesis, water stability and proton conductivity of novel sulfonated polyimides from 4,4'bis(4-aminophenoxy)biphenyl-3,3'-disulfonic acid. Journal of Membrane Science, 230, 111-120 (2004). DOI: $\underline{10.1016 / \mathrm{j} . \mathrm{memsci} .2003 .10 .037}$
[19] Park H. B., Lee C. H., Sohn J. Y., Lee Y. M., Freeman B. D., Kim H. J.: Effect of crosslinked chain length in sulfonated polyimide membranes on water sorption, proton conduction, and methanol permeation properties. Journal of Membrane Science, 285, 432-443 (2006).

DOI: $10.1016 /$ j.memsci.2006.09.026

[20] Sen U., Çelik S. Ü., Ata A., Bozkurt A.: Anhydrous proton conducting membranes for PEM fuel cells based on Nafion/azole composites. International Journal of Hydrogen Energy, 33, 2808-2815 (2008).

DOI: $10.1016 /$ j.ijhydene.2008.03.007

[21] Gruger A., Régis T., Schmatko P., Colomban P.: Nanostructure of Nafion ${ }^{\circledR}$ membranes at different states of hydration: An IR and Raman study. Vibrational Spectroscopy, 26, 215-225 (2001). DOI: $10.1016 / \mathrm{S} 0924-2031(01) 00116-3$

[22] Acar O., Sen U., Bozkurt A., Ata A.: Proton conducting membranes based on poly(2,5-benzimidazole) (ABPBI)-poly(vinylphosphonic acid) blends for fuel cells. International Journal of Hydrogen Energy, 34, 2724-2730 (2009).

DOI: $10.1016 /$ j.ijhydene.2009.01.073

[23] Wilkes C. E., Summers J. W., Daniels C. A., Berard M. T.: PVC handbook. Hanser, München (2005).

[24] Gasa J. V., Weiss R. A., Shaw M. T.: Ionic crosslinking of ionomer polymer electrolyte membranes using barium cations. Journal of Membrane Science, 304, 173180 (2007). DOI: 10.1016/j.memsci.2007.07.031

[25] Antonucci P. L., Aricó A. S., Creti P., Ramunni E., Antonucci V.: Investigation of a direct methanol fuel cell based on a composite Nafion ${ }^{\circledR}$-silica electrolyte for high temperature operation. Solid State Ionics, 125, 431-437 (1999). DOI: $10.1016 / \mathrm{S} 0167-2738(99) 00206-4$

[26] Kreuer K-D.: Proton conductivity: Materials and applications. Chemistry of Materials, 8, 610-641 (1998).

DOI: $10.1021 / \mathrm{cm} 950192 \mathrm{a}$

[27] Pivovar B. S., Wang Y., Cussler E. L.: Pervaporation membranes in direct methanol fuel cells. Journal of Membrane Science, 154, 155-162 (1999).

DOI: $10.1016 / \mathrm{S} 0376-7388(98) 00264-6$

[28] Seeponkai N., Wootthikanokkhan J.: Proton conductivity and methanol permeability of sulfonated poly(vinyl alcohol) membranes modified by using sulfoacetic acid and poly(acrylic acid). Journal of Applied Polymer Science, 105, 838-845 (2007). DOI: 10.1002/app.26116

[29] Kim D. S., Park H. B., Rhim J. W., Lee Y. M.: Proton conductivity and methanol transport behavior of crosslinked PVA/PAA/silica hybrid membranes. Solid State Ionics, 176, 117-126 (2005). DOI: $10.1016 /$ j.ssi.2004.07.011 